Borko Kovačević

\title{
IMENICE SA ZNAČENJEM ARGUMENTA DOGAĐAJA U SAVREMENOM SRPSKOM JEZIKU*
}

\begin{abstract}
Rad se bavi osobinama imenica sa značenjem argumenta događaja u savremenom srpskom jeziku. U pitanju su imenice sa značenjem eksternog argumenta događaja (lovac, birač, vladar..) i imenice sa značenjem internog argumenta događaja (osuđenik, ranjenik...). Puput glagola iz kojih su izvedene i imenica sa značenjem događaja, ove imenice imaju argumentsku strukturu i mogu da imaju negaciju (putem prefiksa ne-). Za razliku od imenica sa značenjem događaja, imenice sa značenjem argumenta događaja ne mogu se modifikovati prilozima, već isključivo pridevima. Značajna karakteristika ovih imenica jeste i to što se argument uz ovakve imenice koje su nastale od glagola koji zahtevaju indirektni objekat u obliku imeničke fraze $u$ dativu $\left(\mathrm{NP}_{\mathrm{DAT}}\right)$ ili imeničke fraze $\mathrm{u}$ instrumentalu $\left(\mathrm{NP}_{\text {INST }}\right)$ realizuje kao imenička fraza u genitivu $\left(\mathrm{NP}_{\mathrm{GEN}}\right)$, a ne kao $\mathrm{NP}_{\mathrm{DAT}}$ ili NP $\mathrm{NNST}_{\text {INT }}$ (što je slučaj sa imenicama koje označavaju događaj).
\end{abstract}

Ključne reči: imenice sa značenjem argumenta događaja, eksterni argument, interni argument, srpski jezik

\section{Uvod}

Imenice sa značenjem argumenta događaja su klasa glagolskih imenica koje označavaju argument događaja, a ne sam događaj koji je obeležen glagolom iz kojeg je imenica izvedena. Tako je od glagola čitati izvedena imenica as značenjem događaja čitanje, ali i imenica sa značenjem argumenta događaja čitalac. Ove imenice označavaju ili eksterni argument događaja, ili interni argument događaja.

Rad je nastao u okviru projekta Savremeni srpski jezik: sintaksička, semantička $i$ pragmatička istraživanja (br. 178004) Filozofskog fakulteta u Novom Sadu i Filološkog fakulteta u Beogradu, koji finansira Ministarstvo nauke Republike Srbije. 
Brojni su primeri imenica sa značenjem eksternog argumenta događaja u srpskom jeziku: lovac, birač, vladar, izdajica, iseljenik, pletilja, mislilac, lutalica, gunđalo, prolaznik, pratnja, obezbeđenje, istražitelj, torokuša... ${ }^{1}$ Ove imenice treba razlikovati od imenica sa značenjem profesije, titule, ili zanimanja. Dok imenice sa značenjem eksternog argumenta događaja imaju obeležje +događaj i argumentsku strukturu, imenice sa značenjem profesije, titule, ili zanimanja su imenice sa obeležjem-događaj i nemaju argumentsku strukturu (Alexiadou i Schäfer 2007). ${ }^{2} \mathrm{Na}$ primer ako je neko učitelj, to ne znači nužno da je on bilo kada bilo koga zaista učio. To može biti neko ko je samo završio određenu učiteljsku školu. Ova imenica karakterizuje nekoga kao učitelja - imenice sa značenjem profesije ili titule imaju značenje karakterizovanja, generičko značenje. Ukoliko se uz neku od ovih imenica upotrebi interni argument, to znači da je u pitanju formalno identična imenica, ali imenica sa značenjem eksternog argumenta događaja, a ne imenica sa značenjem profesije, titule ili zanimanja. Imenica zidar (koja je dvosmislena između značenja eksternog argumenta događaja i referencijalnog značenja zanimanja) upotrebljena u primeru zidari Vavilonske kule ne odnosi se generalno na zidarsku profesiju, već na ljude koji su zaista učestvovali u procesu zidanja Vavilonske kule. Da se radi o različitim klasama imenica potvrđuje i to što imenice sa značenjem eksternog argumenta događaja dopuštaju dodavanje odričnog prefiksa ne-, kao što pokazuju sledeći primeri: plivač - neplivač, pušač nepušač, poznavalac - nepoznavalac, radnik - neradnik. Sa druge strane, (referencijalne) imenice sa značenjem profesije, titule, ili zanimanja to ne dopuštaju: učitelj - *neučitelj, sudac - *nesudac, narednik - *nenarednik, strugar - *nestrugar.

Prema generalizaciji eksternog argumenta (external argument generalization (Schäfer 2008: 173)) imenice sa značenjem eksternog argumenta mogu se odnositi i na druge tematske uloge, a ne samo na agens. Većina ovakvih imenica označava agens, ali postoje i imenice koje označavaju druge tematske uloge. Značenje uzročnika (causer) na primer ima imenica rastvarač. Imenice obožavatelj i ljubitelj nosioci su uloge doživljavača (experiencer). Značenje imaoca (holder) imaju imenice posednik i imalac.

$1 \quad$ Ovde se navodi po jedan primer imenica sa različitim sufiksima.

2 V. takođe Schäfer (2008) i Marchis (2008). 
Manji je broj imenica koje označavaju interni argument događaja. Takve su imenice osuđenik, ranjenik, izaslanik, izgnanik... Razlog zbog kojeg je broj imenica sa značenjem internog argumenta u srpskom jeziku veoma mali (u poređenju recimo sa engleskim ili nemačkim jezikom) jeste to što se u srpskom ređe upotrebljava pasiv. ${ }^{3}$ Izgleda da postoji korelacija između broja ovakvih imenica u određenom jeziku i učestalosti upotrebe pasiva u tom jeziku: što je pasiv razvijeniji, to je i broj imenica sa značenjem internog argumenta veći. ${ }^{4}$

\section{Argumentska struktura}

Imenice koje označavaju argument događaja imaju argumentsku strukturu. Uz imenice koje označavaju eksterni argument događaja može se realizovati interni argument, dok se uz imenice koje označavaju interni argument događaja može realizovati eksterni argument.

U ulozi teme uz imenice sa značenjem eksternog argumenta događaja mogu se naći imenička fraza u genitivu $\left(\mathrm{NP}_{\mathrm{GEN}}\right) \mathrm{u}$ postnominalnom položaju i prisvojni pridev/prisvojna zamenica ispred imenice. $\mathrm{NP}_{\mathrm{GEN}} \cdot{ }^{5}$

Naredni primeri ilustruju realizaciju internog argumenta u obliku

Nisu samo pisci Biblije logoreični.

Svako može da bude čistač ulice, ali pevač, glumac, pisac - ne može! Tako istraživač prirode zamišlja početke hrišćanstva.

... odgajivač i učesnik na brojnim priredbama u kasačkom sportu Srbije, Mališa Vujčić iz Kasidola, uspešni odgajivač i jahač rasnih galopskih grla i pokretač konjičkog sporta u seoskim naseljima.

Sada se jedini ulaz zatvara po tradicionalnom rasporedu, a čuvar

3 Ovo se konstatuje i u Kovačević (2012a).

4 Ovo je i očekivano ukoliko pasiv posmatramo kao gramatičko sredstvo za (komunikativnu) funkciju isticanja (Siewierska 1984; Carlee 2004; Toyota 2008, 2009). Ukoliko u nekom jeziku nije uobičajeno isticanje teme njenim stavljanjem na početak rečenice, na poziciju subjekta, onda nije uobičajeno ni posvećivanje pažnje temi tako što bi se gradile imenice sa značenjem teme (internog argumenta događaja).

5 Svi primeri koji se navode u ovom radu dati su i Kovačević (2012a), a ekscerpirani su iz Korpusa savremenog srpskog jezika na Matematičkom fakultetu u Beogradu. 
ključa je muslimanska porodica kojoj veruju međusobno sumnjičavi hrišćani.

Da ne govorimo o bezrečju Kainovih potomaka i obezrečenosti graditelja - zidara Vavilonske kule.

Dok je on to dokazivao a priori, brod se razbi i sve se podavi osim Panglosa, Kandida i onog ubojice mornara zbog koga se beše utopio plemeniti anabaptist.

Galijski goniči magaraca i mazgari Estramadure - to su ljudi koji treba da paze na njih i da ih uče pameti.

Bio sam redovni dobrovoljni davalac krvi, do sada sam dao krv ukupno 75 puta.

U mleko mogu dospeti i razne druge klice među kojima može biti i zaraznih, te na taj način mleko postaje prenosilac zaraznih bolesti. Radio je to s takvom zadivljujućom veštinom i brzinom da bi mu pozavidele i naše tkalje čuvenih pirotskih ćilima.

Dobili smo obećanje predsednika Putina da će predstavnik Rusije u Pariskom klubu podržati naš zahtev.

Naša je obaveza da na svaki način pomognemo deci branitelja domovine.

U sledećim primerima interni argument uz imenice sa značenjem eksternog argumenta događaja realizovan je kao prisvojni pridev, odnosno prisvojna zamenica:

Ovom svojevrsnom hepeningu prisustvovali su i brojni gosti iz cele Srbije, a među njima su bili i dramski pisac Dušan Kovačević, glumci Bora Todorović i Branislav Lečić, kao i novinar Marko Janković. Jamski kopači su među onima koji imaju dužu ekspoziciju na ovim poslovima u jami.

Njen osnivač je Samjuel Haneman prvi lekar koji je ispitivao delovanje lekova na zdravim osobama.

Ovde treba da odgovaraju oni koji su Plećiću uneli mržnju prema Draškoviću - izjavio je u završnoj reči Draškovićev branilac Momčilo Bulatović.

"Opijen" grčkom kulturom i Aristotelovom filozofijom, Aleksandrov naslednik, Ptolomej I Soter odlučuje da od Aleksandrije napravi novu Atinu. 
Naša nesreća je što su sa padom Beograda, 1521. godine, nestali i njegovi graditelji.

Kad god pročitam neki napis protivnika uvođenja veronauke, nevoljno mi izađe slika tog školskog upravitelja pred oči.

Eksterni argument se uz imenice sa značenjem (internog) argumenta događaja može realizovati u obliku $\mathrm{NP}_{\mathrm{GEN}}$, kao prisvojni pridev/prisvojna zamenica, ili kao grupni pridev. primeri:

Realizaciju eksternog argumenta u obliku $\mathrm{NP}_{\mathrm{GEN}}$ ilustruju sledeći

Izabranik Slađaninog srca je poznati harmonikaš Dragan Dmitrović koji će, kako stvari stoje, morati da se naoruža strpljenjem.

Naime, dok su me u For-de-Fransu smatrali jevrejskim masonom, plaćenikom Amerikanaca, u SAD sam dobio prilično gorku satisfakciju kad sam ustanovio da sam, s njihovog stanovišta, po svoj ...

Naklapao je, uz kafu, sa majorom Boškom Todorovićem, koji je, kao specijalni izaslanik pukovnika Mihailovića, prethodnog dana, iz Foče, stigao u Hercegovinu.

Ovde se oni koji upravljaju državom smatraju opunomoćenicima naroda, i to na osnovu ugovora koji obavezuje obe strane.

No, niko od njih nije imao smelosti da se zauzme za uhapšenika Kontraobaveštajne službe, plašeći se sumnje za saučesništvo, te su se usluge svele na obaveštenja, dobijena preko ...

U narednim primerima eksterni argument je realizovan kao prisvojni pridev/prisvojna zamenica:

Reagovao je onda advokat našeg siromaška i objasnio da je sve bilo baš tako kako stoji u spisima, ali da njegov branjenik nije imao nimalo loše namere. ... žena pa i republikanaca, a otvoreno je nagovestio da se distancira od Bila Klintona u moralnom pogledu, jer je njegov odabranik prvi u Senatu, septembra 1998. godine, izgovorio kako je aktuelni šef države aferom s Monikom Levinski naneo tešku ...

... političkog tela bilo je oličeno u fikciji o dva kraljeva tela, kao i u odgovarajućim ritualima: monarh je bio Božji izabranik na zemlji.

Crteže za kurs radio je jedan mladi slikar, Kličkeov zatvorenik. 
Najmalobrojniji su primeri u kojima se eksterni argument uz imenice sa značenjem internog argumenta događaja realizuje kao grupni pridev: ${ }^{6}$

"On je nemački plaćenik", citira francuska agencija isti izvor, koji je želeo da ostane anoniman.

Američki izaslanik Džejms Perdju i emisar EU Fransoa Leotar preselili su se u međuvremenu u Skoplje kako bi reanimirali politički dijalog ...

Osim argumentske strukture, imenice sa značenjem argumenta događaja, tačnije imenice sa značenjem eksternog argumenta događaja, imaju još neke specifičnosti.

\section{Specifičnosti klase}

Imenice sa značenjem eksternog argumenta događaja u srpskom jeziku poseduju mogućnost dodavanja odričnog prefiksa ne-. Ovo je bitno jer Baker i Vinokurova (2009) kao jednu od razlika između imenica sa značenjem (eksternog) argumenta događaja i imenica sa značenjem događaja (čitanje, dolazak ...), navode da je negacija moguća samo u slučaju druge klase. ${ }^{7}$ Prema njima, imenice sa značenjem argumenta događaja ne mogu da imaju negaciju. Međutim, naredni primeri pokazuju da se u srpskom jeziku, na imenice sa značenjem eksternog argumenta događaja može dodati odrični prefiks ne-:

Naime, svi borci dobrovoljci dobili su pet hektara obradive površine, plac za izgradnju kuće i okućnicu (neborci su dobili tri hektara) i 1921. godine započeli naseljavanje na vojvođanskim napuštenim salašima.

... iz redova birača, trošenje najvećeg dela državnih prihoda na činovništvo, i uopšte žrtvovanje interesa većeg broja nebirača interesima manjeg broja birača.

6 Prema Alexiadou i Stavrou (2002) pod grupnim pridevima podrazumevaju se pridevi koji se odnose na nacionalnost, etnicitet, poreklo, ili bilo koju grupu pojedinaca koji dele neku zajedničku karakteristiku (ideološku, sociološku, geografsku). Takvi su na primer pridevi srpski, francuski, komunistički, demokratski... O grupnim pridevima u srpskom jeziku v. Kovačević (2012b).

7 Autori koriste termine agentivne imenice (agent nominalizations) i događajne imenice (event nominalizations). 
... su dvadeset i dva bibliofila u istoriji američkog predsednikovanja dobila znatno bolje ocene od ostalih koji su važili za nečitače.

Tragično preminuli istražni sudija Okružnog suda u Beogradu bio je neplivač i plašio se vode.

... je dva puta generalni sekretar partije i svima simpatičan kao sportista, nepušač i jedan od retko uvek nasmejanih japanskih političara.

... duboko se otisnuvši u more metafizike, stiže do priča o sveizvesnosti Boga; o egzistenciji apsoluta u kome su sadržani nebiće, biće i svebiće, i to nebiće kao uzrok, a svebiće kao razlog bića; do poimanja nepostojanja kao negativnog ...

Istovremeno ova naredba na najbolji način objašnjava i demantuje pojedinenepoznavaoce odnosa između MUP-a i VJ.

... znalci i neznalci polazili su - samo u različitim pravcima - od toga da se Tigana ne deklinira kao obično srpsko ime, i niko se nije ...

... mogu biti istraživanja koja su sproveli agencija "Stratedžik marketing" i Institut G-17 plus o tome šta korisnici i nekorisnici mobilnih telefona $\mathrm{u}$ Srbiji misle o pruženim uslugama, cenama, kvalitetu i uopšte fenomenu mobilnih telefona.

... znači da su ateisti nemoralni, što je stereotip po kome su svi crnci neradnici, Jevreji prevaranti a homoseksualci pristalice promiskuiteta.

Jedino što u ovakvim slučajevima može da uradi jeste da na adrese neplatiša šalje opomene.

Značajna karakteristika ovih imenica jeste i to što se argument uz ovakve imenice koje su nastale od glagola koji zahtevaju indirektni objekat $\mathrm{u}$ obliku imeničke fraze $\mathrm{u}$ dativu $\left(\mathrm{NP}_{\mathrm{DAT}}\right)$ ili imeničke fraze u instrumentalu $\left(\mathrm{NP}_{\text {INST }}\right.$ ) realizuje kao $\mathrm{NP}_{\mathrm{GEN}}$, a ne kao $\mathrm{NP}_{\mathrm{DAT}}$ ili $\mathrm{NP}_{\text {INST }}$ (što je slučaj sa imenicama koje označavaju događaj). To ilustruju sledeći primeri:

Pravi inspirator i rukovodilac radova na tom gradilištu bio je upravo onaj po kome je kanal opravdano i dobio ime - Josif Staljin.

Dobro se sećam kako je upravitelj moje osnovne škole u strogom centru Beograda, negde 1946. godine, pošto su tadašnje vlasti baš bile definitivno ...

... od nas napisane, prateći njegov život iz godine u godinu, od vremena kada je posle despota Stefana Lazarevića sam postao vladar Srbije, pa do njegove smrti u dubokoj starosti, više puta sam se pitao zašto despot nije proglašen za svetitelja.

Vladao je kao pravi despot, što znači neograničeni gospodar država i svih podanika. 
Po ovome se imenice sa značenjem (eksternog) argumenta događaja razlikuju od imenica sa značenjem događaja. Kao što pokazuju naredni primeri, uz imenice sa značenjem događaja indirektni objekat se realizuje u obliku NP ${ }_{\text {DAT }}$ ili NP ${ }_{\text {INST }}$ (kao i uz glagole iz kojih su imenice izvedene):

To ne dozvoljavaju važeći propisi kojih moraju da se pridržavaju svi nadležni za komandovanje i rukovođenje oružanim snagama.

Ako neko želi na put preko granice automobilom koji nije njegovo vlasništvo, mora da pribavi i dozvolu za upravljanje tuđim vozilom.

Vrlo dobro smo razumeli, dodao je on, da to nije mandat za vladanje Srbijom, nego je to mandat za promene unutar Srbije.

Planeta se opasno, globalno, razboleva od bezumlja i monomanih želja gospdarenja narodom, drăavom, prirodom i planetom.

Ovakvi primeri pokazuju da su imenice sa značenjem eksternog argumenta događaja, kao klasa glagolskih imenica, bliže prototipičnim imenicama u poređenju sa imenicama koje označavaju događaj. Imenice koje označavaju događaj su više glagolske imenice u tom pogledu, nego imenice sa značenjem eksternog argumenta događaja, budući da se uz njih, kao i uz glagole, indirektni objekat realizuje u istom padežu.

O tome da su imenice sa značenjem argumenta događaja manje slične glagolima nego imenice sa značenjem događaja svedoči i mogućnost modifikacije prilozima, koji su tipično glagolski modifikatori, za razliku od prideva koji su tipično imenički modifikatori. Imenice sa značenjem događaja mogu se modifikovati prilogom (čuvanje noću), što nije slučaj sa imenicama sa značenjem argumenta događaja, koje se poput prototipičnih imenica moraju modifikovati pridevom (noćni čuvar, a ne i ${ }^{*} c ̌ u v a r$ noću). ${ }^{8}$

\section{Zaključak}

Imenice sa značenjem argumenta događaja, poput glagola iz kojih su izvedene, i poput imenica sa značenjem događaja, imaju argumentsku strukturu. Ono što ove imenice u savremenom srpskom jeziku povezuje sa glagolima, kao i sa imenicama sa značenjem događaja, jeste i mogućnost negacije (putem dodavanja prefiksa ne-). S obzirom da u drugim ispitivanim jezicima, prema Baker i Vinokurova (2009) ovo nije moguće, po-

$8 \quad$ O ovome se govori i u Kovačević (2012a). 
javu bi trebalo do kraja ispitati. Detaljno proučavanje prirode prefiksa ne- dosta bi toga razjasnilo. Potrebno je videti u kojim sve kontekstima, odnosno uz koje se reči ovaj prefiks može koristiti, kao i kakva su njegova značenja. Temeljnije ispitivanje svojstava glagolskih imenica uz koje se ovaj prefiks može upotrebiti dodatno bi rasvetlilo pomenutu pojavu.

$\mathrm{Za}$ razliku od imenica sa značenjem događaja, uz imenice sa značenjem argumenta događaja koje su nastale od glagola koji zahtevaju indirektni objekat u obliku $\mathrm{NP}_{\text {DAT }}$ ili $\mathrm{NP}_{\text {INST }}$ taj indirektni objekat se realizuje kao $\mathrm{NP}_{\mathrm{GEN}}$, a ne kao $\mathrm{NP}_{\mathrm{DAT}}$ ili $\mathrm{NP}_{\text {INST }}$ (što je slučaj sa imenicama koje označavaju događaj). Imenice sa značenjem argumenta događaja ne mogu se ni modifikovati prilogom, što je moguće kod imenica sa značenjem događaja (i glagola), već se isključivo modifikuju pridevima.

Sve navedene osobine imenica sa značenjem argumenta događaja svrstavaju ove imenice negde između pravih glagolskih imcnica (imenica sa značenjem događaja) i prototipičnih referencijalnih imenica. Otvoreno pitanje na koje bi trebalo dati odgovor u nekim budućim istraživanjima jesu potklase ovih glagolskih imenica. Preciznija potklasifikacija imenica sa značenjem argumenta događaja dala bi još bolji uvid u njihovu prirodu.

\section{Literatura}

Alexiadou, A. \& Schäfer, F. 2007. "Decomposing -er nominalizations". Workshop: Nominalization across languages. http://www.linguistics.ucla.edu/faciliti/wpl/issues/wccfl27/papers/alexiadouetal.pdf

Alexiadou, A. \& Stavrou, M. 2002. "Group Adjectives as pseudo-adjectives: a case study in syntax-morphology interaction”. http:/www. uclm.es/congresos/cgg/abstracts/abstract_alexiadou_stravou.pdf

Baker, M. C. \& Vinokurova, N. 2009. "On agent nominalizations and why they are not like event nominalizations". Language, 85/3, 517-556.

http://www.rci.rutgers.edu

/ mabaker/agent-nominals-web.pdf

Carlee, A. 2004. A Cognitive Approach to the Semantics of the German Passive. New York: Edwin Mellen Press.

Kovačević, B. 2012a. Sintaksičko-semantičke kategorije glagolskih imenica. Doktorska disertacija. Filološki fakultet u Beogradu. 
Kovačević, B. 2012b. "Group adjectives in Serbian". Anali Filološkog fakulteta XXIV/1, 209-217.

Marchis, M. 2008. "The internal structure of the -or nominalization in Romanian". Iz: F.

Schäfer (ed.) SinSpeC (01), Working Papers of the SFB 732, 103117. University of Stuttgart.http://elib.uni-stuttgart.de/opus/volltexte/2008/3551/pdf/SinSpeC 1_7_Marchis.pdf

Schäfer, F. 2008. "Event denoting -er nominalizations in German" Iz: F. Schäfer (ed.)

SinSpeC (01), Working Papers of the SFB 732, 173-187. University of Stuttgart. http://elib.uni-stuttgart.de/opus/volltexte/2008/3554/pdf/ SinSpeC1_10_Schaefer.pdf

Siewierska, A. 1984. Passive: a comparative linguistic analysis. London: Croom Helm.

Toyota, J. 2008. Diachronic changes in the English passive. Baingstoke: Palgrave.

Toyota, J. 2009. "Passive as a tense-aspectual construction revisited: a case of Germanic languages". Groninger arbeiten zur germanistischen linguistik, spezial issue: the passive in germanic languages, 200214.

Borko Kovačević

\section{Summary}

\section{ARGUMENT-DENOTING NOUNS IN SERBIAN}

The paper examines characteristics of argument-denoting nouns in Serbian. There are two groups of these nouns: external argument-denoting nouns (lovac, birač, vladar..) and internal argument-denoting nouns (osuđenik, ranjenik...). These nouns have argument structure and negation (by the ne- prefix). Argument denoting nouns can not be modified by adverbs. They are modified by adjectives. Important characteristic of argument denoting nouns is the fact that argument with these nouns that are derived from the verbs that demand indirect object in $\mathrm{NP}_{\mathrm{DAT}}$ or $\mathrm{NP}_{\mathrm{INST}}$ is realized as $\mathrm{NP}_{\mathrm{GEN}}$, and not as $\mathrm{NP}_{\mathrm{DAT}}$ or $\mathrm{NP}_{\mathrm{INST}}$ (what is the case with event-denoting nouns).

Key words: argument-denoting nouns, external argument, internal argument, Serbian 